University of Nebraska - Lincoln

DigitalCommons@University of Nebraska - Lincoln

Faculty Publications in the Biological Sciences

Papers in the Biological Sciences

2002

\title{
SPECIES RICHNESS, LATITUDE, AND SCALE-SENSITIVITY
}

S. Kathleen Lyons

University of Chicago, katelyons@unl.edu

Michael R. Willig

Texas Tech University

Follow this and additional works at: https://digitalcommons.unl.edu/bioscifacpub

Part of the Biology Commons

Lyons, S. Kathleen and Willig, Michael R., "SPECIES RICHNESS, LATITUDE, AND SCALE-SENSITIVITY" (2002). Faculty Publications in the Biological Sciences. 769.

https://digitalcommons.unl.edu/bioscifacpub/769

This Article is brought to you for free and open access by the Papers in the Biological Sciences at DigitalCommons@University of Nebraska - Lincoln. It has been accepted for inclusion in Faculty Publications in the Biological Sciences by an authorized administrator of DigitalCommons@University of Nebraska - Lincoln. 


\title{
SPECIES RICHNESS, LATITUDE, AND SCALE-SENSITIVITY
}

\author{
S. Kathleen Lyons ${ }^{1,3}$ And Michael R. Willig ${ }^{2}$ \\ ${ }^{1}$ Committee on Evolutionary Biology, University of Chicago, 1025 E. 57th St., Culver Hall 402, \\ Chicago, Illinois 69637-1573 USA, and \\ Division of Mammals, Department of Zoology, Field Museum of Natural History, Lake Shore Drive at Roosevelt Road, \\ Chicago, Illinois 60605 USA \\ ${ }^{2}$ Program in Ecology, Department of Biological Sciences and The Museum, Texas Tech University, \\ Lubbock, Texas 79409-3131 USA, and \\ National Center for Ecological Analysis and Synthesis, University of California, 735 State Street, Suite 300, \\ Santa Barbara, California 93101-3351, USA
}

\begin{abstract}
The latitudinal gradient of species richness is well documented for a variety of taxa in both terrestrial and aquatic environs. Moreover, a number of recent attempts to assess the effects of scale on the relationship have concluded that the latitudinal pattern is scale-invariant. Nonetheless, the power of those approaches is predicated on precise knowledge of the forms of the latitudinal gradient, the area relationship, and their interaction. We used a model developed by J. Pastor, A. Downing, and H. E. Erickson for assessing the effects of scale on the productivity-diversity gradient to avoid such complications. More specifically, for 253 sets of nested quadrats $\left(1000-25000 \mathrm{~km}^{2}\right)$ located throughout the New World, we parameterized the power function and determined whether those parameters varied in a systematic fashion with latitude. Significant latitude-induced monotonic variation in the rate of species accumulation with area ( $z$ parameter) documented scalesensitivity for both bats and marsupials, with $z$ decreasing toward tropical latitudes. Variation in the intercept parameter $(C)$ reflected the latitudinal gradient in richness after adjustment for the latitude-specific effects of area. Both bats and marsupials exhibited strong gradients of richness, with modal values in the tropics. Mechanisms affecting species richness, or the size of ranges and the juxtapositioning of their boundaries, may initiate scale-sensitivity in many systems. A number of mechanistic or phenomenological models (environmental, geometric constraint, and Rapoport-rescue hypotheses) thought to produce the latitudinal gradient also enhance the likelihood of scale-sensitivity. Consequently, investigations of other macroecological gradients of richness (e.g., elevation, depth, and productivity) that should be affected by such factors are probably also scale-sensitive.
\end{abstract}

Key words: areography; bats; biodiversity; geographical ecology; latitudinal gradients; macroecology; marsupials; North America; Rapoport's rule; scale-sensitivity; South America.

\section{INTRODUCTION}

Consideration of broad geographic patterns is critical to conceptual development and empirical evaluation of hypotheses in ecology, as well as in conservation and evolutionary biology (Brown 1995, Rosenzweig 1995, Gaston 1996, Mauer 1999). This is especially evident with respect to three interdependent relationships: latitudinal gradients of diversity (Willig 2000), latitudinal gradients in species range size (Brown et al. 1996), and relationships between diversity and productivity (Waide et al. 1999). All three patterns are interconnected as a consequence of geographic constraints and the effects of area. Latitudinal patterns of species richness emerge as a consequence of factors affecting the distribution of individual species. Moreover, energetic correlates of latitude (i.e., productivity and tempera-

Manuscript received 11 May 2000; revised 11 January 2001; accepted 9 February 2001; final version received 13 March 2001

${ }^{3}$ Present address: 167 Castetter Hall, Department of Biology, University of New Mexico, Albuquerque, New Mexico 87131 USA. E-mail: sklyons@unm.edu ture) affect the fitness of organisms by modifying the costs of survivorship and reproduction in a geographically explicit fashion (Hall et al. 1992). Because geographic patterns are quantified based on samples of different areas, considerations of scale-sensitivity are needed prior to exploring issues of generality and extrapolation. Indeed, studies of scale (see Kolasa and Pickett 1991, Peterson and Parker 1998) have paralleled the emergence of macroecology as a distinct discipline (Allen and Hoekstra 1991, Palmer and White 1994, Schneider 1994), and it is becoming clear that patterns and their mechanistic bases require consideration of scale in all of its manifestations (Pastor et al. 1996, Lyons and Willig 1999, Gross et al. 2000, Scheiner et al. 2000, Mittlebach et al. 2001; J. M. Chase and M. A. Leibold, unpublished manuscript).

\section{Latitudinal gradients of diversity}

Since the voyages of Darwin and Wallace, biologists have been fascinated with the high species diversity of tropical regions compared to that in temperate or boreal zones. In many ways, this fascination with tropical di- 
versity catalyzed the conceptual development of the theory that currently constitutes modern ecology. Moreover, growing concern about the loss of diversity, especially in tropical regions, has led to the rapid development of the science of conservation biology. Documenting the way in which diversity differs across the globe and understanding the mechanisms that produce such variation are critical steps in the design of global conservation strategies and the implementation of regional management plans.

The mid-1950s to early 1960s saw the emergence of rigorous quantification of broad-scale relationships between species richness and latitude (e.g., Fischer 1960). Within the next 25 years, scientists convincingly documented the ubiquity of gradients in which species richness increased toward tropical areas (for an overview, see Willig 2000). Similar gradients also were documented for diversity of higher taxa (e.g., genera, families, and orders). Indeed, the increase in species richness for terrestrial and marine environments was quantified successfully for a wide variety of taxonomic groups, such as mammals, birds, reptiles, amphibians, fishes, tunicates, crustaceans, mollusks, brachiopods, corals, foraminiferans, and vascular plants. Exceptions usually represent lower levels in a systematic hierarchy (e.g., seals, penguins, and sandpipers with polar peaks in richness; voles, salamanders, ichneumonid wasps, and coniferous trees with temperate peaks in richness) for which other groups of equivalent rank within the same higher taxon often are restricted to lower latitudes. Nonetheless, the higher taxon often exhibits a tropical maximum in species richness.

\section{Mammalian macroecology}

Although caution must be used in interpreting results from any particular taxon, the study of mammals has contributed substantially to understanding the latitudinal gradient in diversity and the mechanisms that may give rise to it. Although initial studies detailing latitudinal gradients in mammalian richness focused on North America (e.g., Hagmeier and Stults 1964, Simpson 1964, Hagmeier 1966, Wilson 1974, McCoy and Connor 1980, Pagel et al. 1991), an increasing number of studies recently have quantified latitudinal patterns of richness for South America (e.g., Mares and Ojeda 1982, Ruggiero 1994), or for both North and South America (e.g., Willig and Selcer 1989, Willig and Sandlin 1991, Kaufman 1995, Willig and Gannon 1997, Kaufman and Willig 1998). Because of corroborative evidence for latitudinal trends in both continents, it is likely that patterns are affected by environmental correlates of latitude (e.g., available energy, temperature, and climatic variation) rather than by the unique shape of continents or their evolutionary history.

Alternatively, geometric constraints may have a profound impact on the form of latitudinal gradients of species richness. Indeed, modal patterns of diversity peaking in the tropics can be a consequence of the bounded nature of terrestrial and aquatic habitats, rather than a consequence of environmental, evolutionary, or historical phenomena. Both simulation (i.e., Colwell and Hurtt 1994, Pineda and Caswell 1998) and analytical models (i.e., Willig and Lyons 1998, Lees et al. 1999) suggest that species richness of a biota should increase toward the center of a shared geographic domain in a quasi-parabolic or parabolic fashion, as a consequence of the random placement of species ranges (i.e., the mid-domain effect of Colwell and Lees 2000). Such views may be particularly relevant as null models: deviations from the modality effected by geometric constraints rather than modality itself require mechanistic explanations related to ecological, evolutionary, or historical factors (Willig and Lyons 1998, Colwell and Lees 2000).

In comparing empirical latitudinal gradients of richness with predictions of a geometrically constrained model in the New World, Willig and Lyons (1998) accounted for $69-95 \%$ of the variation in species richness for bats and marsupials. Nonetheless, systematic deviations from the null distribution were observed for both taxa. In particular, the model overestimated bat species richness near the edges of the domain and underestimated richness near the center of the domain. In contrast, the model consistently overestimated species richness for marsupials at all latitudes. Although both taxa gradually increased in species richness toward the tropics, the manner in which they deviated from the predictions of the null model were in sharp contrast, and the residuals were not related to the area of the continent at each latitude.

\section{Scale}

Interest in spatial scale as it affects latitudinal gradients of species richness mostly has revolved around the use of quadrats or bands of various sizes and dimensions to assess gradients of species richness (McCoy and Connor 1980, Willig and Selcer 1989, Willig and Sandlin 1991, Anderson and Marcus 1993, Kaufman and Willig 1998). The range of sizes upon which gradients were quantified generally was small (e.g., $2.5^{\circ}$ vs. $5^{\circ}$ bands or quadrats), or adjustments of richness for area were based on linear and polynomial algorithms, even though the ecological literature is replete with examples showing that richness often increases with area as a power function. In some cases, adjustments of richness were counterintuitive because latitude and area can be confounded as a result of geography. In North America, for example, the width of latitudinal bands decreases toward the tropics (North America is essentially triangular in shape) whereas the species richness of mammals increases toward the tropics. Hence, controlling for area via covariance analysis or analysis of residuals effectively inflates the richness of large areas and deflates the richness of small areas! If the signal of area related to the size of a sampling quadrat or band is to be eliminated, more refined de- 
signs must be employed to adjust for differences in the spatial scale of sampling.

In an attempt to rectify this situation, Lyons and Willig (1999) developed a model that united aspects of theory relating species richness to latitude, area, and their interaction (i.e., scale-dependence). The model assumed that the effects of area were best represented by the power function, whereas the effects of latitude were well represented by an exponential decay function. The experimental design involved a number of sets of nested quadrats within latitudinal bands. Inclusion of a multiplicative term in the general model represented scale-dependence. The multiplicative term was not significant in analyses for either bats or marsupials, suggesting that the way in which species richness increased with decreasing latitude was consistent at all spatial scales between 1000 and $25000 \mathrm{~km}^{2}$. Moreover, the effect of area at this range of scales also was not significant, suggesting that species generally co-occur as discrete faunas, or that distribution maps, often derived from the extrapolation of species ranges based on ecological or geopolitical boundaries, produce homogeneous faunas at these spatial scales.

Herein, we adapt the quantitative model of scaledependence for the productivity-diversity relationship that was developed by Pastor et al. (1996) to refine our understanding of scale-sensitivity in latitudinal gradients of species richness. Pastor et al. (1996) disentangled the interaction between productivity and scale by documenting that the intercept and slope of the logarithmic form of the power function are related to productivity. More specifically, $z$ is related negatively to productivity, whereas $C$ is related positively to productivity. This trade-off represents a mechanism that can produce a unimodal pattern of variation in species richness. In an analogous fashion, we examine the way in which latitude affects parameters of the power function, produce an area-free gradient of diversity, and explore differences between tropical and extratropical regions in the context of scaling.

\section{Methods And Materials}

\section{The faunas}

Bats and marsupials represent markedly different mammalian body plans (Eisenberg 1981, Vaughan 1986) and evince quite different evolutionary histories and contemporary ecological characteristics. This makes them ideal for evaluating the impact of scalesensitivity on latitudinal gradients. Moreover, much is known about gradients of richness and range size in these two groups.

Bats ( $\sim 250$ New World species) occur throughout most of North and South America (Willig and Selcer 1989, Willig and Sandlin 1991, Lyons and Willig 1997, Willig and Lyons 1998), with many species having extensive ranges that encompass a large portion of both continents (Lyons and Willig 1997). Moreover, bat spe- cies richness peaks above the equator at about $10^{\circ} \mathrm{N}$ (Willig and Lyons 1998). In contrast, the majority of New World marsupials ( $\sim 80$ species) are limited to Central and South America, with only one species (Didelphis virginiana) penetrating very far into North America (Gardner 1973, Lyons and Willig 1997, Willig and Gannon 1997). Current ecological diversity of New World marsupials is much less than that prior to the Great American Interchange (Simpson 1980, Stehli and Webb 1985). Moreover, most marsupials have relatively restricted ranges, probably due to their relatively small size, lack of vagility, and poor dispersal abilities (Lyons and Willig 1997). These factors combine to produce a platykurtic distribution with maximum richness at approximately $20^{\circ} \mathrm{S}$ (Willig and Gannon 1997 , Willig and Lyons 1998).

\section{Data acquisition}

Sampling methodologies generally followed Lyons and Willig (1999). More specifically, distribution maps for bats were based on Hall (1981) for North and Central America and on Koopman (1982) for South America. Similarly, distribution maps for marsupials were based on Hall (1981) for North and Central America and on Streilein (1982) for South America. To update distributions of both taxa in South America, we referred to Eisenberg (1989) and Redford and Eisenberg (1992). A detailed rationale for inclusion of taxa based on systematic considerations appears in Lyons (1994).

To avoid biases in adjusting for area, our analyses were based only on quadrats that wholly contain land (sensu Rosenzweig 1995). More specifically, nested sets of quadrats $\left(25,000 \mathrm{~km}^{2}, 20,000 \mathrm{~km}^{2}, 15,000 \mathrm{~km}^{2}\right.$, $10,000 \mathrm{~km}^{2}$, and $1000 \mathrm{~km}^{2}$ ) were superimposed systematically on an equal-area projection map of the New World. Species richness of a quadrat was considered to be the number of species whose geographic ranges overlapped a quadrat. This sampling design predisposes species-area relationships to conform to the power function. Centers of the nested quadrats were located along each $5^{\circ}$ meridian of longitude at $2.5^{\circ}$ latitudinal intervals (Fig. 1). To avoid sampling bias, we limited the number of locations (253) by the size of the largest quadrat in the nested series that would not overlap adjacent quadrats of the same size. Because of the rigorous requirements of the sampling scheme, a few latitudinal bands have only one set of nested quadrats. Although this may lead to a few locally biased estimates, the more general concerns raised by Rosenzwieg (1995) necessitate such a sampling protocol.

\section{Data analysis}

In general, we adhered to the methodologies of Pastor et al. (1996). For each nested set of quadrats, we estimated parameters of the power function, $S=C A^{z}$ (Arrhenius 1921, 1923), where $S$ is species richness of a quadrat, $A$ is quadrat area, and $C$ and $z$ are constants fitted by least-squares analysis of the logarithmic form 


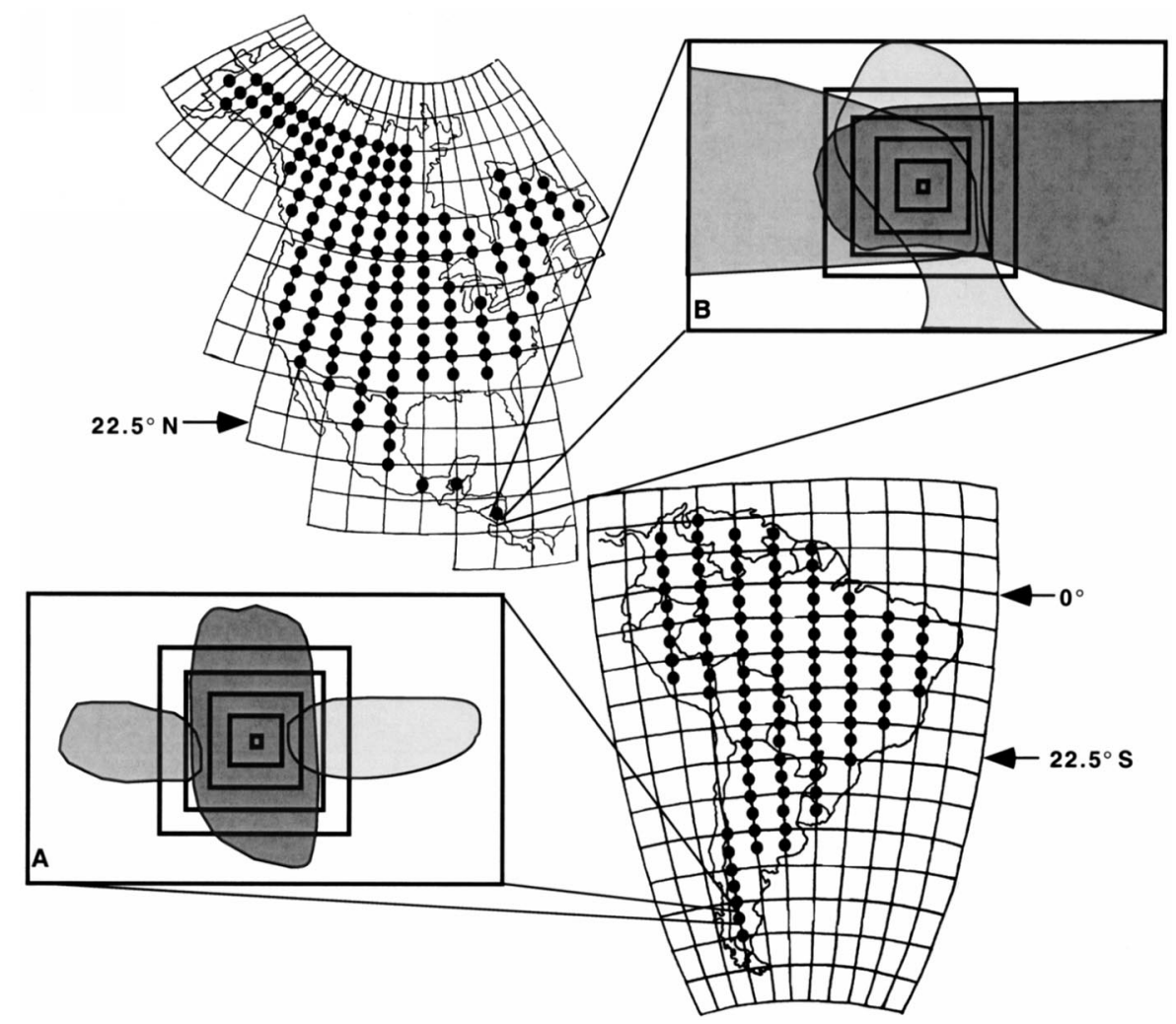

FIG. 1. Equal-area projection maps of North and South America with closed circles placed at every $5^{\circ}$ longitude and $2.5^{\circ}$ latitude to indicate the position of the nested sets of quadrats used in this study. All quadrats are fully contained within the landmass. Insets A (temperate zone) and B (tropical zone) are graphical representations of differences in the way in which species ranges and range edges overlap. For bats and marsupials, ranges are larger and overlap more in the tropics (Lyons and Willig 1997), diminishing the rate at which species richness increases with area. In temperate zones, ranges are smaller and overlap less, resulting in an enhanced rate of species accumulation with area.

of the power relationship. Clearly, $z$ represents the rate at which $S$ increases with $A$, and $C$ represents species richness in a quadrat of standard size (i.e., unit area).

To assess the degree to which latitude affects parameters of the power function, we performed two nonparametric analyses (i.e., Spearman's rank correlations). In the first, we evaluated whether the magnitude of $z$ was associated with variation in latitude. In the second, we evaluated whether the magnitude of $\ln C$ was associated with variation in latitude. The first analysis assessed scale-sensitivity; a significant relationship implies that the effect of area on species richness is latitude-dependent. The second analysis provided a scale-free assessment of the latitudinal gradient in species richness. Because scale-sensitivity and the latitudinal gradient of species richness may differ in North and South America for historical, ecological, or evolutionary reasons, we conducted correlation analyses separately in North and South America.

The number of quadrats at each latitude varies with the width of North and South America; consequently, the aforementioned analyses weighted latitudes with broad longitudinal extents more than those with narrow longitudinal extents (hereafter "quadrat-weighted anal- yses"). To avoid this bias, and to equally represent each latitude in analyses (hereafter "band-weighted analyses"), we followed Lyons and Willig (1999) and calculated mean species richness for each quadrat size in each latitudinal band. Subsequently, we estimated parameters of the power function for each latitude separately, based on mean values of $S$ and $A$, and assessed scale-sensitivity as before, based on regression analyses. As a result, only a single species-area curve was calculated for each latitude in band-weighted analyses.

\section{RESULTS}

We successfully extended the analytical model of Pastor et al. (1996) to evaluate scale-sensitivity in the latitudinal gradient of species richness. Although our analyses are predicated on a particular relationship between $S$ and $A$ (i.e., the power function), they are not constrained by a particular functional relationship between $S$ and latitude. In general, qualitative results from "quadrat-weighted analyses" and "band-weighted analyses" were identical for bats and for marsupials. Consequently, we only present the results for "bandweighted analyses" and include consideration of "quadrat-weighted analyses" if they provide additional 
TABLE 1. Values of $r^{2}$ indicate goodness-of-fit for speciesarea curves at each latitude (band-weighted analyses). Blank cells indicate latitudes at which marsupials do not occur.

\begin{tabular}{|c|c|c|}
\hline \multirow[b]{2}{*}{ Latitude } & \multicolumn{2}{|c|}{$r^{2}$} \\
\hline & Bats & Marsupials \\
\hline $65^{\circ} \mathrm{N}$ & 0.583 & \\
\hline $62.5^{\circ} \mathrm{N}$ & 0.861 & \\
\hline $60^{\circ} \mathrm{N}$ & 0.930 & \\
\hline $57.5^{\circ} \mathrm{N}$ & 0.916 & \\
\hline $55^{\circ} \mathrm{N}$ & 0.933 & \\
\hline $52.5^{\circ} \mathrm{N}$ & 0.869 & \\
\hline $50^{\circ} \mathrm{N}$ & 0.964 & 0.175 \\
\hline $47.5^{\circ} \mathrm{N}$ & 0.973 & 0.104 \\
\hline $45^{\circ} \mathrm{N}$ & 0.945 & 0.931 \\
\hline $42.5^{\circ} \mathrm{N}$ & 0.852 & 0.785 \\
\hline $40^{\circ} \mathrm{N}$ & 0.999 & 0.957 \\
\hline $37.5^{\circ} \mathrm{N}$ & 0.972 & 0.931 \\
\hline $35^{\circ} \mathrm{N}$ & 0.990 & 0.931 \\
\hline $32.5^{\circ} \mathrm{N}$ & 0.983 & 0.960 \\
\hline $30^{\circ} \mathrm{N}$ & 0.992 & 0.931 \\
\hline $27.5^{\circ} \mathrm{N}$ & 0.904 & 0.391 \\
\hline $25^{\circ} \mathrm{N}$ & 0.955 & 0.936 \\
\hline $22.5^{\circ} \mathrm{N}$ & 0.944 & 0.980 \\
\hline $20^{\circ} \mathrm{N}$ & 0.996 & 0.936 \\
\hline $17.5^{\circ} \mathrm{N}$ & 0.993 & 0.973 \\
\hline $12.5^{\circ} \mathrm{N}$ & 0.904 & 0 \\
\hline $10^{\circ} \mathrm{N}$ & 0.739 & 0.570 \\
\hline $7.5^{\circ} \mathrm{N}$ & 0.981 & 0.809 \\
\hline $5^{\circ} \mathrm{N}$ & 0.997 & 0.965 \\
\hline $2.5^{\circ} \mathrm{N}$ & 0.981 & 0.969 \\
\hline $0^{\circ}$ & 0.984 & 0.918 \\
\hline $2.5^{\circ} \mathrm{S}$ & 0.990 & 0.934 \\
\hline $5^{\circ} \mathrm{S}$ & 0.983 & 0.992 \\
\hline $7.5^{\circ} \mathrm{S}$ & 0.971 & 0.959 \\
\hline $10^{\circ} \mathrm{S}$ & 0.986 & 0.993 \\
\hline $12.5^{\circ} \mathrm{S}$ & 0.950 & 0.956 \\
\hline $15^{\circ} \mathrm{S}$ & 0.978 & 0.970 \\
\hline $17.5^{\circ} \mathrm{S}$ & 0.964 & 0.879 \\
\hline $20^{\circ} \mathrm{S}$ & 0.951 & 0.886 \\
\hline $22.5^{\circ} \mathrm{S}$ & 0.894 & 0.717 \\
\hline $25^{\circ} \mathrm{S}$ & 0.949 & 0.902 \\
\hline $27.5^{\circ} \mathrm{S}$ & 0.995 & 0.932 \\
\hline $30^{\circ} \mathrm{S}$ & 0.967 & 0.481 \\
\hline $32.5^{\circ} \mathrm{S}$ & 0.786 & 0.680 \\
\hline $35^{\circ} \mathrm{S}$ & 0.981 & 0.973 \\
\hline $37.5^{\circ} \mathrm{S}$ & 0.812 & 0.925 \\
\hline $40^{\circ} \mathrm{S}$ & 0.924 & 0.915 \\
\hline $42.5^{\circ} \mathrm{S}$ & 0.863 & 0.932 \\
\hline $45^{\circ} \mathrm{S}$ & 0.729 & 0.366 \\
\hline $47.5^{\circ} \mathrm{S}$ & 0.931 & 0.589 \\
\hline $50^{\circ} \mathrm{S}$ & 0.931 & 0.589 \\
\hline
\end{tabular}

insight into patterns or mechanisms. Goodness-of-fit was determined for all band-weighted analyses as the $r^{2}$ of a linear regression between $\ln S$ and $\ln A$ (Table $1)$.

\section{Scale}

Regardless of analytical approach, marsupials (Fig. 2A, B) and bats (Fig. 2C, D) exhibited significant scalesensitivity (Table 2 ) in the sense that the rate $(z)$ of species accumulation with area depended on taxon and latitude. Nonetheless, the degree of scale-sensitivity differed between continents. The pattern for bats exhibited less noise and reflected little heterogeneity among quadrats at the same latitude, whereas the pat- tern for marsupials exhibited more variation. In particular, for a broad band of latitudes representing the tropics $\left(22.5^{\circ} \mathrm{N}\right.$ to $22.5^{\circ} \mathrm{S}$; shaded areas of Fig. 2), marsupials exhibited little systematic variation in $z$ with latitude, compared to the situation in extratropical regions. More generally, the rate of change in $z$ is faster in extratropical areas than in the tropics for bats and marsupials. Nonetheless, a number of locations in North America appear as outliers (see points at $20^{\circ}$ to $25^{\circ} \mathrm{N}$ latitude) for latitudinal trends in both $C$ and $z$, and should be interpreted with caution. These outliers may be an artifact of the small numbers of quadrats that could be accommodated within these latitudinal bands or have distinct biological importance, as these locations occur at the interface of tropical and temperate biomes in Mexico in the vicinity of the Trans Mexican Volcanic Belt, a region of particular concern for conservation efforts (Arita et al. 1997).

In South America, $z$ scaled positively and significantly with latitude for both taxa, whereas latitudinal scaling of $z$ differed between taxa in North America (Table 2). More specifically, $z$ scaled negatively and significantly with latitude for marsupials, but evinced no significant association with latitude for bats. For marsupials, all but five of the locations in North America had only Didelphis virginiana, the common opossum (the Xs in Fig. 2B). If such locations are not considered in a comparable analysis, then the remaining four latitudinal bands $\left(17.5^{\circ}\right.$ to $25^{\circ} \mathrm{N}$ of Fig. $\left.2 \mathrm{~A}\right)$ evince a nonsignificant association. For bats, only a few locations contained a single species (i.e., the few north temperate Xs of Fig. 2D). When these data are excluded from analysis, the nonsignificant association persists. For both taxa, the three latitudes at the interface between tropical and extratropical areas $\left(20^{\circ}, 22.5^{\circ}\right.$, and $25^{\circ} \mathrm{N}$ ) have a strong impact on the negative sign of Spearman's rank correlation coefficient. Notably, two of these latitudes $\left(20^{\circ}\right.$ and $\left.22.5^{\circ} \mathrm{N}\right)$ contain only one set of nested quadrats. Therefore, the $z$ values for these bands may be biased. In fact, the extratropical latitudinal gradient of $z$ for bats species in North America reflects the patterns in South America quite accurately (compare open and solid circles in unshaded or extratropical regions of Fig. 2C).

\section{Standardized latitudinal gradient of richness}

Marsupials (Fig. 3A, B) and bats (Fig. 3C, D) each exhibited a strong relationship between species richness and latitude after we controlled for area, although marsupials exhibit higher variability among quadrats at the same latitude than do bats. Regardless of analytical approach, each taxon has a distinctive tropical maximum. For marsupials, tropical regions evince little to no change in richness with increasing latitude, compared to the situation in extratropical areas where species richness increases rapidly (compare shaded and unshaded regions of Fig. 3). For bats, species richness does not attain a broad plateau in the tropics, but rather 

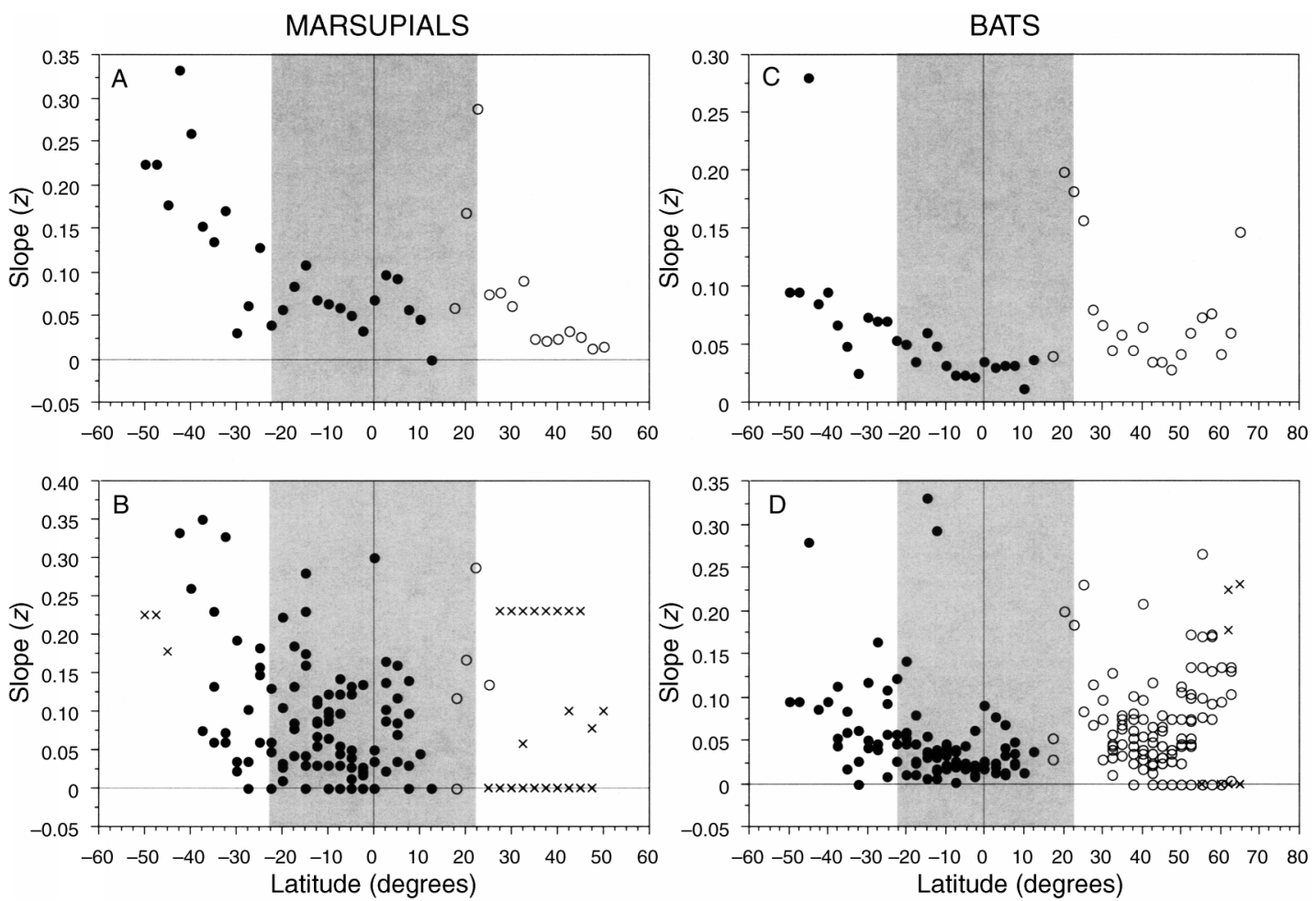

FIG. 2. The relationship between the slope $(z)$ of the species-area curves generated for the nested sets of quadrats for marsupials and bats and latitude (negative numbers represent South latitudes, and positive numbers represent North latitudes). (A, C) Results for band-weighted analyses (see Data analysis for explanation); (B, D) results from quadrat-weighted analyses. Open circles represent quadrats in North America; solid circles represent quadrats in South America. X's represent situations for which values of $z$ were based on quadrats that contained one species at most.

continues to increase with decreasing latitude, although at a slightly slower rate than seen in extratropical areas. Locations at the interface of tropical and temperate biomes in the vicinity of the Trans Mexican Volcanic Belt reflect abrupt transitions in species richness.

\section{DISCUSSION}

Ecological systems are organized into a hierarchy of spatial and temporal scales that affect linkages between

TABLE 2. Spearman's rank correlations for band-weighted analyses of the relationship between latitude and the slopes $(z)$ and intercepts $(\ln C)$ of species-area curves for marsupials and bats.

\begin{tabular}{crrrrr}
\hline \hline & \multicolumn{2}{c}{ South America } & & \multicolumn{2}{c}{ North America } \\
\cline { 2 - 3 } \cline { 5 - 6 } Taxa & $\rho$ & $P$ & & $\rho$ & \multicolumn{1}{c}{$P$} \\
\hline Marsupials & & & & & \\
$z$ & $\mathbf{0 . 7 0 7}$ & $<0.001$ & & $-\mathbf{0 . 7 9 2}$ & 0.004 \\
ln $C$ & $-\mathbf{0 . 7 6 3}$ & $<0.001$ & & 0.046 & 0.868 \\
Bats & & & & & \\
$z$ & $\mathbf{0 . 7 9 3}$ & $<0.001$ & & -0.206 & 0.392 \\
ln $C$ & $\mathbf{- 0 . 9 8 4}$ & $<0.001$ & & $-\mathbf{0 . 8 6 0}$ & $<0.001$ \\
\hline
\end{tabular}

Notes: Significant relationships are emphasized with boldface font. Results of analyses for marsupials in North America are dominated by a large number of sites at which only $D$. virginiana occurs (Fig. 2B), and are likely spurious (see Potential effects of sampling method for details). pattern and process. The dynamics of such systems at a lower scale affects the dynamics of systems at higher levels and vice versa (Allen and Starr 1982, O'Neill 1989). A few ecological studies at the level of populations or communities have found scale to be relatively unimportant (e.g., Stiling et al. 1991, Aronson 1992). Nonetheless, it is increasingly apparent that results at one spatial or temporal scale may not necessarily be recapitulated at larger or smaller scales (Kerfoot and DeAngelis 1989, Rose and Leggett 1990, Hanski 1991, Camus and Ojeda 1992, Gascon and Travis 1992, Levin 1992, Pastor et al. 1996, Guo and Berry 1998, Kelt et al. 1999, Waide et al. 1999, Gross et al. 2000, Scheiner et al. 2000, Mittlebach et al. 2001).

\section{Scale}

A number of previous investigations of the latitudinal gradient in diversity have attempted to control for differences in area; however, most have used arithmetic standardization (e.g., Anderson and Marcus 1993), linear or polynomial regression (e.g., Willig and Sandlin 1991), or analyses of residuals from linear regression (e.g., Kaufman and Willig 1998). Such adjustments are, at best, approximations of the fundamental species-area relationship embodied by the power function (Arrhenius 1921, 1923). In general, the 

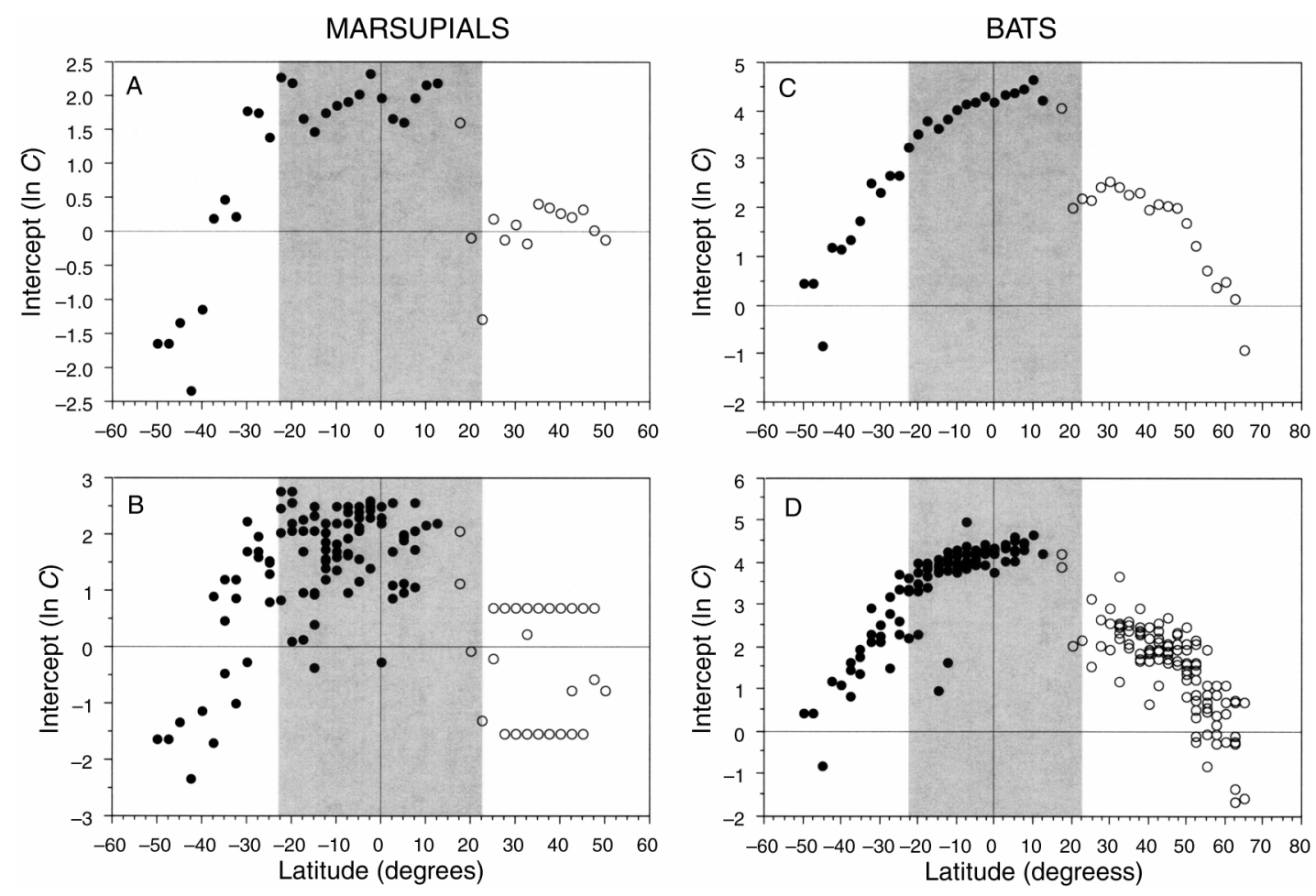

FIG. 3. The relationship between the intercept $(\ln C)$ of species-area curves generated for the nested sets of quadrats for marsupials and bats and latitude (negative numbers represent South latitudes (B, D) results and positive numbers represent North latitudes). (A, C) Results from band-weighted analyses (see Data analysis for explanation); (B, D) results from quadratweighted analyses. Open circles represent quadrats in North America; solid circles represent quadrats in South America.

power function has enjoyed extensive application to studies concerning the dependence of species richness on area for both island and mainland systems (MacArthur and Wilson 1967, Gilbert 1980, Rosenzweig 1995). Nonetheless, Lyons and Willig (1999) were the first to assess the joint effects of area and scale-dependence on the latitudinal gradient of richness, using the power function for a set of nested quadrats. Although in the broadest of contexts they developed a model which could accommodate a variety of algorithms for both areal and latitudinal effects, their application of the model to New World bats and marsupials was based on an exponential decay algorithm for the latitudinal gradient. This model may have been a reasonable first approximation for bats $\left(R^{2}=0.87\right)$, but it failed to capture the essence of the gradient for marsupials $\left(R^{2}=0.60\right)$, with substantial deviations from expectation in subtropical to temperate South America as well as in extratropical regions of North America.

From a conceptual perspective, the most limiting feature of the Lyons and Willig (1999) approach concerned the modeling component that embodied scale-dependence. In essence, the interaction term in their model required scale-dependence to appear as a multiplicative term that was proportional to the product of a latitudinal decay process and an areal power function. As a result, failure to detect significant scale-dependence in lati- tudinal gradients of richness could result from an incorrect mathematical form for either component, or if nonmultiplicative interactions characterize scale-dependence. In essence, the Lyons and Willig (1999) approach may be too restrictive to have broad utility. Modification of the approach of Pastor et al. (1996) avoids these limitations, and includes a number of significant advantages. The form of the latitudinal gradient does not prejudice detection of scale-dependence. In our model, $\ln C$ represents area-controlled and scaleindependent variation in species richness; it is a standardized value that is adjusted for the latitude-specific values of the power function. For example, plots of $1 n$ $C$ vs. latitude are scale-free and area-adjusted visualizations of the latitudinal gradient in diversity whose mathematical form can be assessed by a variety of statistical models. In contrast, systematic variation in $z$ with latitude represents scale-sensitivity. If the effect of area is invariant with latitude, then $z$ and latitude should evince no systematic association. By assessing the latitudinal association of $z$ via nonparametric algorithms, we can detect any general scale-sensitivity that exhibits a monotonic trend.

\section{Potential effects of sampling method}

Previous studies rightly have been criticized because richness data for quadrats not wholly contained on land 
were included in statistical analyses (Rosenzweig 1995). The sampling method in this study was designed specifically to avoid this problem. Moreover, calculation of species-area curves for nested sets of quadrats requires the accurate measurement of land area in each quadrat. Keeping quadrats of uniform sizes and full of land easily accomplishes this goal. However, an undesirable side effect is that latitudes occurring where the continents are narrow can only accommodate a single set of nested quadrats. The contributions of these latitudes to general patterns must be scrutinized carefully and interpreted with caution, as $z$ values may be biased. The direction of bias would depend upon the way in which spatial distributions of species and species richness are affected by longitudinal variation within latitudinal bands.

\section{Differences between taxa and among latitudes}

Latitudinal differences in $z$ within taxa, as well as differences in $z$ between taxa at the same latitude, may be affected by species richness. More specifically, any fixed absolute increase in the number of species with increasing area will have a greater effect on the magnitude of $z$ in species-poor areas and biotas than in species-rich areas or biotas. This differential effect is an inherent consequence of the power function itself. Changes in area are the same for all nested quadrats, as a consequence of sampling design. Thus, the magnitude of $z$ is determined wholly by the differences in the logarithm of $S$ among areas. For any pair of nested quadrats, the change in the logarithm of species richness $(\Delta \ln S)$ is given by

$$
\Delta \ln S=\ln S_{2}-\ln S_{1}=\ln \left(S_{2} / S_{1}\right) .
$$

In general, if the absolute change in species richness is the same at two locations (i.e., $s$ ), but the locations differ with respect to $S_{1}, \Delta \ln S$ will be greater at the location with smaller $S_{1}$ because $\left(S_{1}+s\right) / S_{1}$ decreases as $S_{1}$ increases (Fig. 4). As a consequence, we would expect, a priori, that speciose biotas (e.g., bats) generally have smaller values of $z$ than do depauperate biotas (e.g., marsupials), and that, within a biota, species-rich tropical latitudes should have lower values of $z$ than do their extratropical counterparts. Moreover, small variations in species richness due to factors other than area or latitude would have larger effects on variation in $z$ in species-poor than in species-rich locations or biotas. Empirical patterns for bats and marsupials with respect to latitude illustrate all of these phenomena.

\section{Latitudinal gradients of richness, range size, and scale}

Two general mechanisms are consistent with the empirical data for bats and marsupials concerning latitudinal gradients in species richness (Willig and Lyons 1998), species range size (Lyons and Willig 1997), and scale-sensitivity (this research). The mechanisms are
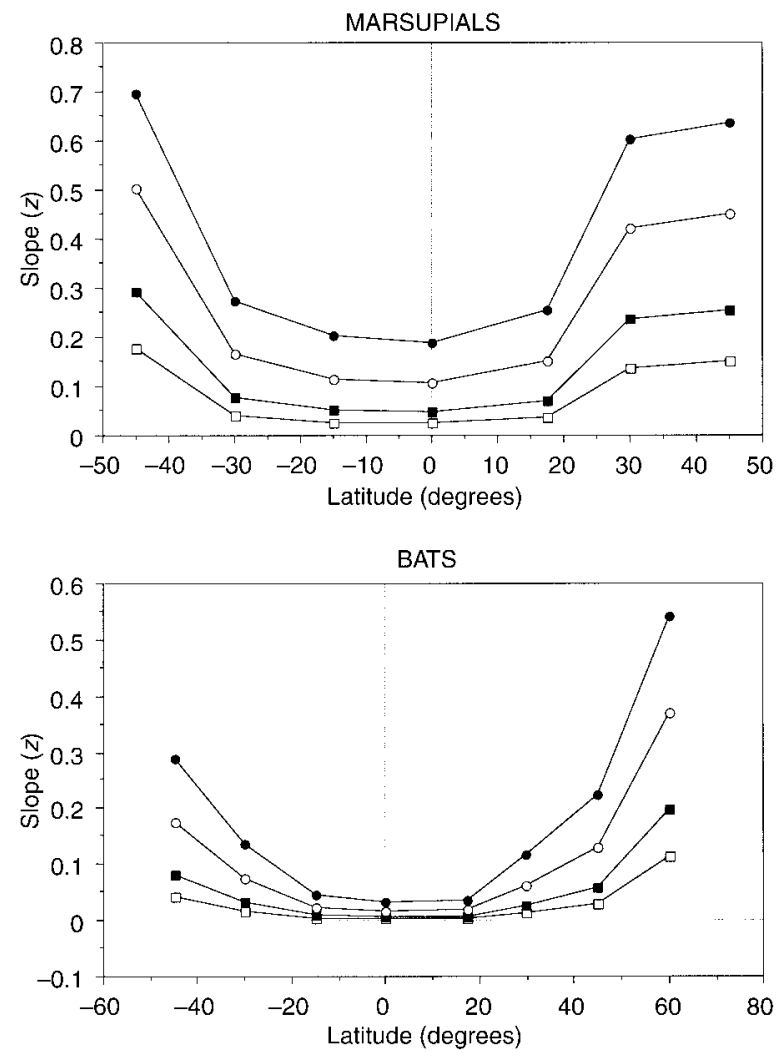

FIG. 4. Graphical representation of the variation in slope (z) expected with latitude as a consequence of systematic variation in species richness $(S)$. Mean richness of a quadrat was calculated for bats and marsupials at regular intervals of latitude (based on empirical data) and used as the number of species in the smallest quadrat. Richness was systematically augmented as quadrat size increased, and values of $z$ were estimated for species-area curves. Symbols correspond to an absolute change in one species (open squares), an absolute change in two species (solid squares), an absolute change in five species (open circles), and an absolute change in 10 species (solid circles). Clearly, scale-dependence, as measured by $z$, is expected solely as a consequence of systematic variation in species richness with latitude.

not mutually exclusive and, in fact, probably reinforce each other to some extent. The environmental mechanism includes considerations of area, energy, and temperature. The geographic constraint mechanism includes the effects of stochastic process operating in a bounded domain (i.e., the New World).

Environmental mechanism.-Compared to other phytogeographic regions, the tropics in the New World has more area (Rosenzweig and Sandlin 1997; but see Rohde 1997, 1998), greater climatic homogeneity (Terborgh 1973), and higher solar irradiation (MacArthur 1972). Large area and climatic homogeneity should enhance the likelihood that tropical species will have broad geographic ranges. Moreover, differences in species composition among sites should be less in the tropics than elsewhere because of climatic homogeneity. Finally, high solar irradiation in tropical sites facilitates 
high species richness by decreasing the costs of metabolism (temperature correlates) and increasing the rate of energy supply (productivity) in general (Rosenzweig 1995; D. M. Kaufman, D. F. Sax, and J. H. Brown, unpublished manuscript).

Geometric constraint mechanism.-Alternatively, a random placement of species ranges with respect to latitude, constrained only by the boundaries of the hemisphere, gives rise to gradients of species richness (Colwell and Hurtt 1994, Willig and Lyons 1998) and species range size (Colwell and Hurtt 1994, Lyons and Willig 1997), which both peak in the center of the latitudinal domain. Because central portions of the latitudinal domain contain more broadly ranging species than do distal portions of the latitudinal domain, turnover among quadrats should be less there. Moreover, the geometric constraint mechanism has implications for the accumulation of species within a set of nested quadrats (Fig. 1, insets A and B). Central portions of a domain (i.e., the tropics) that contain more broadly ranging species (Fig. 1, inset B) will have a lower rate of accumulation of species as area increases because a larger proportion of species ranges will overlap all quadrats in a nested set. In contrast, more distal portions of a domain (i.e., the temperate zones) that contain more narrowly ranging species (Fig. 1, inset A) will have higher rates of accumulation among nested quadrats because there is a higher likelihood that any given range will overlap only part of a nested set of quadrats. If the mid-domain effect (Colwell and Lees 2000) applies to longitudinal gradients within latitudinal bands, then a single set of nested quadrats in the center of a narrow band may have a lower rate of species accumulation. Thus, these rates may be decoupled from the latitude, per se, at which they occur.

Contributions to scale-sensitivity. - The New World tropics are distributed approximately in the center of the hemisphere; hence, geometric-constraint models produce qualitative predictions similar to those based on environmental mechanisms. Indeed, factors that enhance the likelihood of scale-sensitivity may do so by increasing systematic variation in $S$ or by creating systematic differences in the distribution of species boundaries in space. The environmental mechanism, as well as the geometric constraint mechanism, does both.

In a different context, J. M. Chase and M. A. Leibold (unpublished manuscript) provide a mechanism for scale-dependence in the productivity-diversity relationship that has considerable relevance to latitudinal gradients, especially because productivity is highly correlated with latitude. For theoretical reasons based on either a resource competition model or a trophic model, variation in productivity results in a unimodal pattern of richness when the focus of analysis is a small area (i.e., a locality). More importantly for purposes here, at higher productivities, differences in the species composition of localities at the same productivity increase (i.e. beta diversity becomes large). Consequent- ly, larger scale patterns (i.e., those derived from sampling units that encompass multiple localities) evince a relationship between richness and productivity that is positive and monotonic. Not only do theoretical models predict such scale-dependence, but empirical data for plants and animals in wetlands of Michigan corroborate it. Hence, two aspects of either of two different mechanisms (e.g., competitive or predator-prey dynamics) can differentially affect the diversity of a region (e.g., gamma diversity), depending on productivity (or its surrogate, latitude). One aspect effects the species composition of local sites and another aspect enhances differentiation among sites. As sampling units get larger, species accumulate at one rate at low productivity, whereas they accumulate at a different rate at high productivity. Hence, $C$ and $z$ of the power function would differ systematically among sites and would be detected as scale-sensitivity by our algorithms.

\section{Rapoport's rule}

When the latitudinal extents of the ranges of a group of species decrease from polar to tropical environs, the taxon is said to adhere to Rapoport's rule (Rapoport 1982, Stevens 1989). A number of mechanisms (i.e., land area, climatic variability, differential extinction, competition, and biogeographic boundary hypotheses) have been advanced to account for the rule, and considerable controversy surrounds the generality of the pattern as well as the validity of the mechanisms thought to give rise to it (Rohde 1996, Gaston 1999, Gaston et al. 1998). Nonetheless, in the initial incarnation of the rule, Stevens (1989) suggested a hybrid of two mechanisms (i.e., the Rapoport-rescue hypothesis) to primarily effect the rule. First, climatic variability should select for large ranges in species occupying extratropical regions, and small ranges in species occupying tropical areas (i.e., the Rapoport effect). Second, the rescue of local populations from extinction (e.g., source-sink dynamics) on the boundary of a species distribution would proportionally enhance the ratio of the rescue effect area to geographic range area for tropical species more than for their extratropical counterparts (i.e., the rescue effect). Hence, an interconnected pair of gradients is created, with species richness increasing and species range size decreasing toward the tropics. If true, predictions cannot be made about gradients in scale-sensitivity because increasing $S$ toward the tropics should diminish $z$, whereas a higher frequency of small ranges in the tropics should enhance $z$. Depending on the form and strength of these two tendencies, this could result in increasing, decreasing, modal, or no gradients of scale-sensitivity.

In an insightful reconsideration of Rapoport's rule, Taylor and Gaines (1999) ironically have demonstrated, via simulation analyses, that the Rapoport effect alone, and the Rapoport effect in combination with a rescue effect (Brown and Kodric-Brown 1977), actually pro- 
duces a gradient of diversity that decreases rather than increases toward the tropics. The tropics of the New World would be depauperate in a world governed by Rapoport's rule! In this sense, the Rapoport-induced gradient of decreasing species richness and size of species ranges toward equatorial regions would produce a gradient of scale-sensitivity in which $z$ increased toward the tropics, the opposite of the patterns observed for both bats and marsupials with respect to richness, range size, and scale.

\section{Overview}

We have developed a statistical method for assessing the effects of area on the relationship between latitude and species richness. Moreover, we have documented that the latitudinal gradient is scale-sensitive for both bats and marsupials in the New World. To properly remove the effects of area, it is necessary to obtain estimates of both $C$ and $z$ from nested sampling units for which latitude does not vary. Previous models (e.g., Lyons and Willig 1999) may be too restrictive. They require a priori knowledge of the form of the latitudinal gradient and can only detect scale-dependence that emerges as a consequence of the multiplicative interaction of assumed forms of the latitudinal and areal gradients in richness. As a consequence, they may fail to properly detect the simple effects of area as well as its scale-dependence.

We have shown that mechanisms that systematically enhance species richness may perforce effect scalesensitivity. Similarly, factors that systematically affect the distribution of species borders may cause scalesensitivity as well. Some of the models that have been used to account for the latitudinal gradient in diversity affect both richness and range size, such that the effect of scale has a predictable outcome. For example, geometric constraint and environmental mechanisms both produce declining gradients in the rate of species accumulation with area toward the tropics. The opposite trend for rates of accumulation (as well as $S$ ) occurs if the Rapoport-rescue model, as envisioned by Taylor and Gaines (1999), is in operation. Finally, if the Rapoport-rescue model, as originally envisioned by Stevens (1989), occurs, then no a priori predictions concerning patterns of scale-sensitivity are possible, because increasing richness toward the tropics deflates $z$, whereas decreasing range size inflates $z$.

Elevational (e.g., Stevens 1992, Lees 1996), bathymetric (e.g., Pineda and Caswell 1998) and other environmental gradients in richness may be affected by mechanisms similar to those hypothesized to affect the latitudinal gradient. To the extent that this is true, we expect scale-sensitivity to be a general phenomenon. As such, scale is a factor of considerable importance in macroecologcial investigations, and may be pervasive.

\section{ACKNOWLEDGMENTS}

For critical reviews of earlier versions of the manuscript and of ideas contained herein, we thank J. Alroy, S. Andelman, J. Bascompte, O. Bjornstad, M. Foote, R. Holt, M. Lomolino, K. Rohde, S. Scheiner, and one anonymous reviewer. A number of institutions graciously provided financial support during the genesis of this project. In particular, the research was conceived and completed while M. R. Willig (Sabbatical Fellow) and S. K. Lyons (Working Group Participant) were in residence at the National Center for Ecological Analysis and Synthesis, a center funded by NSF (DEB-9421535), the University of California at Santa Barbara, and the state of California. A Developmental Leave was provided to M. R. Willig by the Provost's Office, Texas Tech University, with additional support from grant BSR-8811902 from the National Science Foundation to the Institute for Tropical Ecosystems Studies, University of Puerto Rico, and the International Institute of Tropical Forestry (Southern Forest Experiment Station) as part of the Long-Term Ecological Research Program in the Luquillo Experimental Forest. S. K. Lyons was supported by a Science to Achieve Results (STAR) Graduate Fellowship from the EPA (award number U 915414). The University of Chicago provided additional resources.

\section{Literature Cited}

Allen, T. G. H., and T. B. Starr. 1982. Hierarchy: perspectives for ecological complexity. University of Chicago Press, Chicago, Illinois, USA.

Allen, T. G. H., and T. W. Hoekstra. 1991. The role of scaling of ecological systems under analysis. Pages 47-84 in J. K. Kolasa and S. T. A. Pickett, editors. Ecological heterogeneity. Springe-Verlag, New York, New York, USA.

Anderson, S., and L. F. Marcus. 1993. Effect of quadrat size on measurements of species density. Journal of Biogeography 20:421-428.

Arita, H. T., F. Gigueroa, A. Frisch, P. Rodrigues, and K. Santos-del-Prado. 1997. Geographical range size and the conservation of Mexican mammals. Conservation Biology 11:92-100.

Aronson, R. B. 1992. Biology of a scale-independent predator-prey interaction. Marine Ecology Progress Series 89: $1-13$.

Arrhenius, O. 1921. Species and area. Journal of Ecology 9: 95-99.

Arrhenius, O. 1923. On the relation between species and area-a reply. Ecology 4:90-91.

Brown, J. H. 1995. Macroecology. University of Chicago Press, Chicago, Illinois, USA.

Brown, J. H., and A. Kodric-Brown. 1977. Turnover rates in insular biogeography: effects of immigration on extinction. Ecology 58:445-449.

Brown, J. H., G. C. Stevens, and D. M. Kaufman. 1996. The geographic range: size, shape, boundaries, and internal structure. Annual Review of Ecology and Systematics 27: 597-623.

Camus, P. A., and F. P. Ojeda. 1992. Scale-dependent variability of density estimates and morphometric relationships in subtidal stands of the kelp Lessonia trabeculata in northern and central Chile. Marine Ecology Progress Series 90: 193-200.

Colwell, R. K., and G. C. Hurtt. 1994. Nonbiological gradients in species richness and a spurious Rapoport effect. American Naturalist 144:570-595.

Colwell, R. K., and D. C. Lees. 2000. The mid-domain effect: geometric constraints on the geography of species richness. Trends in Ecology and Evolution 15:70-76.

Eisenberg, J. F. 1981. The mammalian radiations. University of Chicago Press, Chicago, Illinois, USA.

Eisenberg, J. F. 1989. Mammals of the Neotropics. The north- 
ern Neotropics. Volume 1. University of Chicago Press, Chicago, Illinois, USA.

Fischer, A. G. 1960. Latitudinal variations in organic diversity. Evolution 14:64-81.

Gardner, A. L. 1973. The systematics of the genus Didelphis (Marsupialia: Didephidae) in North and Middle America. Special Publication Number 4. The Museum, Texas Tech University, Lubbock, Texas, USA.

Gascon, C., and J. Travis. 1992. Does the spatial scale of experimentation matter? A test with tadpoles and dragonflies. Ecology 73:2237-2243.

Gaston, K. J. 1996. Biodiversity: a biology of numbers and difference. Blackwell Science, Oxford, UK.

Gaston, K. J. 1999. Why Rapoport's rule does not generalize. Oikos 84:309-312.

Gaston, K. J., T. M. Blackburn, and J. I. Spicer. 1998. Rapoport's rule: time for an epitaph? Trends in Ecology and Evolution 13:70-74.

Gilbert, F. S. 1980. The equilibrium theory of island biogeography: fact or fiction? Journal of Biogeography 7:209235.

Gross, K. L., M. R. Willig, L. Gough, R. Inouye, and S. B. Cox. 2000. Species diversity in relation to productivity: patterns within and among herbaceous plant communities Oikos (In press).

Guo, Q., and W. L. Berry. 1998. Species richness and biomass: dissection of the hump-shaped relationship. Ecology 79:2555-2559.

Hagmeier, E. M. 1966. A numerical analysis of the distributional patterns of North American mammals. II. Re-evaluation of the provinces. Systematic Zoology 15:279-299.

Hagmeier, E. M., and C. D. Stults. 1964. A numerical analysis of the distributional patterns of North American mammals. Systematic Zoology 13:125-155.

Hall, C. A., J. A. Stanford, and F. R. Hauer. 1992. The distribution and abundance of organisms as a consequence of energy balances along multiple environmental gradients. Oikos 65:377-390

Hall, E. R. 1981. The mammals of North America. Second edition. John Wiley, New York, New York, USA.

Hanski, I. 1991. The functional response of predators: worries about scale. Trends in Ecology and Evolution 6:141142.

Kaufman, D. M. 1995. Diversity of New World mammals: universality of the latitudinal gradients of species and bauplans. Journal of Mammalogy 76:322-334.

Kaufman, D. M., and M. R. Willig. 1998. Latitudinal patterns of mammalian species richness in the New World: the effects of sampling method and faunal group. Journal of Biogeography 25:795-805.

Kelt, D. A., P. L. Meserve, B. D. Patterson, and B. K. Lang. 1999. Scale dependence and scale independence in habitat associations of small mammals in southern temperate rainforest. Oikos 85:320-324.

Kerfoot, W. C., and D. L. DeAngelis. 1989. Scale-dependent dynamics: zooplankton and the stability of freshwater food webs. Trends in Ecology and Evolution 4:167-171.

Kolasa, J., and S. T. A. Pickett, editors. 1991. Ecological heterogeneity. Springer-Verlag, New York, New York, USA.

Koopman, K. F. 1982. Biogeography of bats of South America. Pages 273-302 in M. A. Mares and H. H. Genoways, editors. Mammalian biology in South America Special Publication Series Number 6, Pymatuninng Laboratory of Ecology, University of Pittsburgh, Pittsburgh, Pennsylvania, USA.

Lees, D. C. 1996. The Périnet effect? Diversity gradients in an adaptive radiation of butterflies in Madagascar (Satyringe: Mycalesina) compared with other rainforest taxa.
Pages 479-490 in W. R. Lourenço, editor. Biogéographie de Madagascar. Éditions de l'ORSTOM, Bondy, France.

Lees, D. C., C. Kremen, and L. Andriamampianina. 1999. A null model for species richness gradients: bounded range overlap of butterflies and other rainforest endemics in Madagascar. Biological Journal of the Linnean Society 67:529584.

Levin, S. A. 1992. The problem of pattern and scale in ecology. Ecology 73:1943-1967.

Lyons, S. K. 1994. Areography of New World bats and marsupials. Thesis. Texas Tech University, Lubbock, Texas, USA.

Lyons, S. K., and M. R. Willig. 1997. Latitudinal patterns of range size: methodological concerns and empirical evaluations for New World bats and marsupials. Oikos 79:568580.

Lyons, S. K., and M. R. Willig. 1999. A hemispheric assessment of scale dependence in latitudinal gradients of species richness. Ecology 80:2483-2491.

MacArthur, R. H. 1972. Geographical ecology: patterns in the distribution of species. Harper \& Row, Princeton, New Jersey, USA.

MacArthur, R. H., and E. O. Wilson. 1967. The theory of island biogeography. Princeton University Press, Princeton, New Jersey, USA.

Mares, M. A., and R. A. Ojeda. 1982. Patterns of diversity and adaptation in South American Hystricognath rodents. Pages 393-432 in M. A. Mares and H. H. Genoways, editors. Mammalian biology in South America Special Publication Series Number 6, Pymatuning Laboratory of Ecology, University of Pittsburgh, Pittsburgh, Pennsylvania, USA.

Maurer, B. A. 1999. Untangling ecological complexity: the macroscopic perspective. University of Chicago Press, Chicago, Illinois, USA.

McCoy, E. D., and E. F. Connor. 1980. Latitudinal gradients in the species diversity of North American mammals. Evolution 34:193-203.

Mittlebach, G. G., C. F. Steiner, S. M. Scheiner, K. L. Gross, H. L. Reynolds, R. B. Waide, M. R. Willig, S. I. Dodson, and L. Gough. 2001. What is the observed relationship between species richness and productivity? Ecology 82: 2381-2396.

O'Neill, R. V. 1989. Hierarchy theory and global change. (SCOPE 35) Pages 29-45 in T. Rosswall, R. G. Woodmansee, and P. G. Risser, editors. Scales and global change. John Wiley, New York, New York, USA.

Pagel, M. D., R. M. May, and A. R. Collie. 1991. Ecological aspects of the geographical distribution and diversity of mammalian species. American Naturalist 137:791-815.

Palmer, M. W., and P. S. White. 1994. Scale dependence and the species-area relationship. American Naturalist 144: 717-740.

Pastor, J., A. Downing, and H. E. Erickson. 1996. Speciesarea curves and diversity-productivity relationships in beaver meadows of Voyageurs National Park, Minnesota, USA. Oikos 77:399-406.

Peterson, D. L., and V. T. Parker, editors. 1998. Ecological scale: theory and applications. Columbia University Press, New York, New York, USA.

Pineda, J., and H. Caswell. 1998. Bathymetric species-diversity patterns and boundary constraints on vertical range distributions. Deep-Sea Research 45:83-101.

Rapoport, E. H. 1982. Areography: geographical strategies of species. Pergamon Press, New York, New York, USA.

Redford, K. H., and J. F. Eisenberg. 1992. Mammals of the Neotropics. The southern cone. Volume 2. University of Chicago Press, Chicago, Illinois, USA.

Rohde, K. 1996. Rapoport's Rule is a local phenomenon and 
cannot explain latitudinal gradients in species diversity. Biodiversity Letters 3:10-13.

Rohde, K. 1997. The larger area of the tropics does not explain latitudinal gradients in species diversity. Oikos 79: $169-172$.

Rohde, K. 1998. Latitudinal gradients in species diversity. Area matters, but how much? Oikos 82:184-190.

Rose, G. A., and W. C. Leggett. 1990. The importance of scale to predator-prey spatial correlations: an example of Atlantic fishes. Ecology 71:33-43.

Rosenzweig, M. L. 1995. Species diversity in space and time. Cambridge University Press, Cambridge, UK.

Rosenzweig, M. L., and E. A. Sandlin. 1997. Species diversity and latitudes: listening to area's signal. Oikos 80:172175.

Ruggiero, A. 1994. Latitudinal correlates of the sizes of mammalian geographical ranges in South America. Journal of Biogeography 21:545-559.

Scheiner, S. M., S. B. Cox, M. R. Willig, G. G. Mittlebach, C. W. Osenberg, and M. Kaspari. 2000. Species richness: scale effects and Simpson's paradox. Evolutionary Ecology Research 2:791-802.

Schneider, D. C. 1994. Quantitative ecology: spatial and temporal scaling. Academic Press, San Diego, California, USA.

Simpson, G. G. 1964. Species density of North American recent mammals. Systematic Zoology 13:57-73.

Simpson, G. G. 1980. Splendid isolation: The curious history of South American mammals. Yale University Press, New Haven, Connecticut, USA.

Stehli, F. G., and S. D. Webb. 1985. The great American biotic interchange. Plenum Press, New York, New York, USA.

Stevens, G. C. 1989. The latitudinal gradient in geographical range: how so many species coexist in the tropics. American Naturalist 133:240-256.

Stevens, G. C. 1992. The elevational gradient in altitudinal range: an extension of Rapoport's latitudinal rule to altitude. American Naturalist 140:893-911.

Stiling, P., A. Throckmorton, J. Silvanima, and D. R. Strong
1991. Does spatial scale affect the incidence of density dependence? a field test with insect parasitoids. Ecology 72:2143-2154.

Streilein, K. E. 1982. Behavior, ecology, and distribution of South American marsupials. Pages 231-250 in M. A. Mares and H. H. Genoways, editors. Mammalian biology in South America. Special Publication Series Number 6, Pymatuning Laboratory of Ecology, University of Pittsburgh, Pittsburgh, Pennsylvania, USA.

Taylor, P. H., and S. D. Gaines. 1999. Can Rapoport's rule be rescued? Modeling causes of the latitudinal gradient in species richness. Ecology 80:2474-2482.

Terborgh, J. 1973. On the notion of favorableness in plant ecology. American Naturalist 107:481-501.

Vaughan, T. A. 1986. Mammalogy. Third edition. Saunders College Publishing, Philadelphia, Pennsylvania, USA.

Waide, R. B., M. R. Willig, C. F. Steiner, G. Mittelbach, L. Gough, S. I. Dodson, G. P. Juday, and R. Parmenter. 1999 The relationship between productivity and species richness. Annual Review of Ecology and Systematics 30:257-300.

Willig, M. R. 2000. Latitudinal gradients in diversity. Pages 701-714 in S. Levin, editor. Encyclopedia of Biodiversity. Volume 3. Academic Press, San Diego, California, USA.

Willig, M. R., and M. R. Gannon. 1997. Gradients of species density and turnover in marsupials: A hemispheric perspective. Journal of Mammalogy 78:756-765.

Willig, M. R., and S. K. Lyons. 1998. An analytical model of latitudinal gradients of species richness with an empirical test for marsupials and bats in the New World. Oikos 81: 93-98.

Willig, M. R., and E. A. Sandlin. 1991. Gradients of species density and turnover in New World bats: a comparison of quadrat and band methodologies. Pages 81-96 in M. A. Mares and D. J. Schmidly, editors. Latin American mammals: their conservation, ecology, and evolution. University of Oklahoma Press, Norman, Oklahoma, USA.

Willig, M. R., and K. W. Selcer. 1989. Bat species density gradients in the New World: a statistical assessment. Journal of Biogeography 16:189-195.

Wilson, J. W. 1974. Analytical zoogeography of North American mammals. Evolution 28:124-140. 